\title{
Goods Logistics Management Based on the Line of Transport Operators
}

\author{
Yi-peng LI and Chun-yan XIE \\ School of Information and Safety Engineering, Zhong nan University of Economics \\ and Law, Wu Han 430073, China
}

Keywords: Supply chain management, Logistics management, Information technology, Transport business queuing model.

\begin{abstract}
The supply chain management based on electronic commerce has gradually become the mainstream management mode of the enterprises. Logistics management is very important in the whole supply chain management. It is the link between suppliers and manufacturers, manufacturers and distributors, vendors and users. Therefore, the study of logistics management is of great significance to the current economic development .This paper focuses on distributed product supply and transportation, link product supply and transportation for both sides to freight transportation information center, analysis of product providers, integrator (freight Information Center), transport operators between the relationship. Based on the model of product supply chain management in the line of freight forwarder, Under the premise of the centralized product supply chain. Using information technology to discuss how to coordinate the supply and the loading capacity of the supplier and the transport provider ,to Maximize the benefits.
\end{abstract}

\section{Introduction}

Logistics enterprises in our country is still in its infancy, a lot of logistics and distribution centers only exist in large shopping malls or chain stores, and did not spread to all walks of life, but also did not form a complete logistics system. The theoretical research on logistics management is not much, the current logistics management can't adapt to the rapid development of China's commodity economy, so the research of logistics management is very urgent.

Especially in the more than and 20 years of reform and opening up, the transportation infrastructure has been developed rapidly, which has led to the prosperity of the automobile transportation industry. China is a vast land and rich natural resources, but due to differences in the north and south of latitude across the wide and three order terrain lead to regional distribution of resources, with the rapid development of China's economy, people's living standards gradually improve, the demand for all kinds of materials also showed a rising trend, which led to the exchange of goods between regions. But with the material exchange is closely linked to the logistics management, but the current logistics management on our country, whether it is theoretical or practical aspects of the existence of defects. Such as integrators received supplier delivery information, the forwarder to supplier the goods shipped to the designated supplier to, when transport operators in within the stipulated time arrived at the supplier, and suppliers due to unforeseen factors can't be delivered on time and to transport goods, then transport both abandoned while walking or patience and other goods will produce unnecessary spending, and as integrators of information department at this time should be how to coordinate the relationship between the supplier and transportation? In this paper, based on the reality of life, this paper studies the product 
logistics management based on the line of freight forwarder, which has strong practical significance.

Research on product logistics management, Yao Jianming has studied the service characteristics of SMC model in the" Supply chain scheduling optimization under the mode of mass customization" and establish the dynamic optimization mathematical model, using ant colony algorithm to solve the model. Finally, the paper analyzes the feasibility of the algorithm. Xu Gang and Qin enter through the construction of service value model to study the influence of information asymmetry between suppliers and manufacturers on the supply chain information sharing and trust decision. It is proposed that the service value of the supplier is positively correlated with the authenticity of the information shared by the manufacturer. Illustrate the interests of mutual benefit and win-win. Wang Wenlong, Liu Xin - Mei, Wang Tao was established based on customer queuing model of service supply chain, this paper analyzes the centralized and decentralized logistics service provider and integrator of optimal service capacity and the best services to the market price, found in the cost sharing contract both parties' profits can reach the maximum. Jos Crespo de Carvalho, etc. from the perspective of strategic services, the evolution of logistics and supply chain management. Its ultimate aim is to prove that logistics and supply chain management is a kind of service and value creation, and is not a simple change and trading. Chang Chang-Hsing in a study of global logistics management and based on the bicycle manufacturing by literature review method, study the global logistics management, analysis the operational status of bicycle industry in Taiwan City, and with the present situation of the global shipping industry into line compared to Taiwan logistics management put forward constructive suggestions, for Taiwan to accelerate the development of a global logistics center.

In view of the above research, this paper to integrators as the center, as a connecting link between suppliers and carriers, integrators main role lies in the timely transmission of information between the two sides, coordinate the interests between the two sides, the source of revenue to the suppliers and transporters to give the information costs. The supplier is responsible for the provision and storage of the goods, and the carriers only need to deliver the goods to the designated place of the supplier at the specified time, and get the freight from the supplier. The information provided by the supplier is random, and the carrier is in line for the delivery of the goods in accordance with the principle of first to the first served. By constructing the product logistics management model, the optimal quantity of goods (m) and the unit freight rate (R), in the premise of the centralized product logistics, to maximize the benefits of the supplier and the carrier.

\section{Model Assumptions and Parameter Setting}

Transport operators in line product logistics management should pay attention to the following points: (1)in the logistics management, with time as the standard determining vendors, integrators, transporters are illegal, whether to need to pay the cost of delay; (2) the supplier provides goods and is responsible for the storage of goods; (3) Integration just as the third party, relying on information technology to connect suppliers and transporters. Integrators must first the relevant departments in the local business license approved prior to the business, at the same time to get the truck information;(4) the supplier to provide the goods information integrator, issued a request to the car carriers, the driver according to the actual situation (such as the number of goods, time limit, freight and so on) to consider whether to grab a single (from the taxi drops software) at 
the same time, transport operators to grab a single reply integrators, does not exist the goods without a car; (5)The transportation business after a single grab if did not arrive in time, the delay time of loading, according to the value of the goods and the length of the delay compensation for suppliers; (6) Here's transport industry using the same model of truck, truck loading is uniform, in accordance with the arrival time of loading and wait in line;(7) transport operators mainly by individuals, which are independent of the individual owners. The relationship between the three is shown in Figure 1.

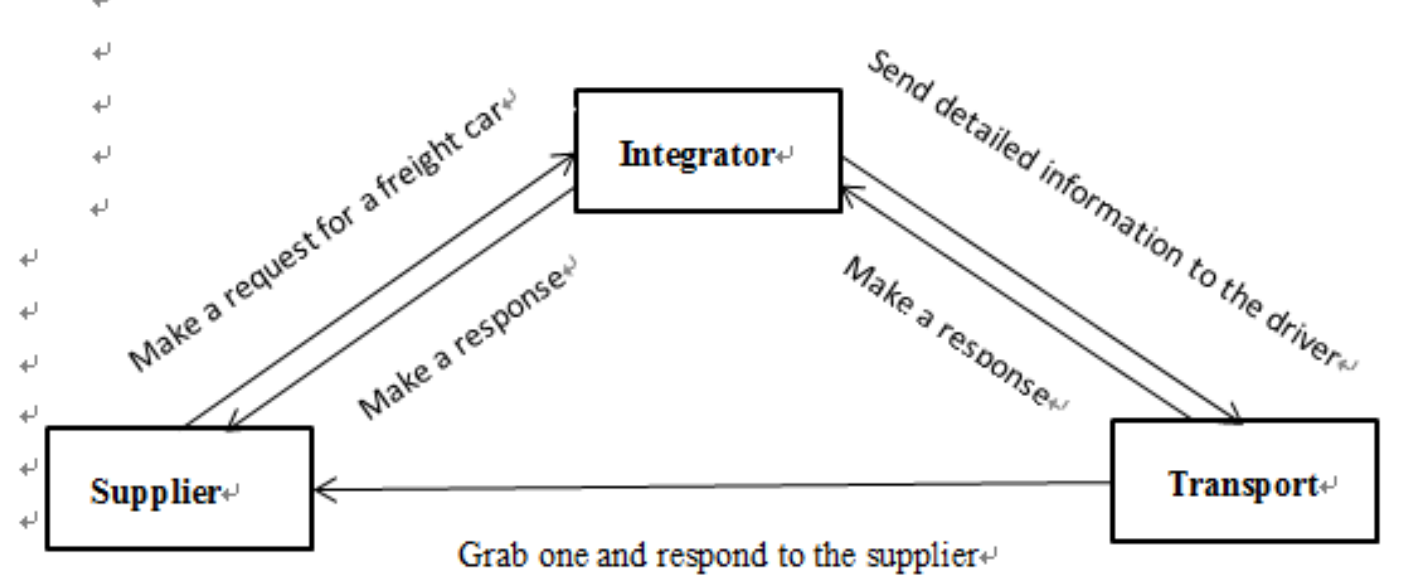

Figure 1 Main structure of logistics

According to the above analysis, we make the following assumptions, as shown in Table 1

Table 1 Basic variable table

\begin{tabular}{|c|c|c|}
\hline Variable & Meaning & Functional relation \\
\hline $\mathrm{m}$ & $\begin{array}{l}\text { The maximum quantity of goods supplied by the } \\
\text { supplier at each time }\end{array}$ & \\
\hline $\mathrm{n}$ & Shelf life of goods & \\
\hline $\mathrm{a}$ & Price of each ton of cargo & \\
\hline$\mu$ & Supplier's average delivery rate & \\
\hline$c_{w}$ & Unit waiting cost & \\
\hline$c_{a}$ & Unit giving up cost & \\
\hline $\mathrm{L}(\mathrm{m})$ & The number of car for giving up waiting & $L(m)=\max (\lambda t-\mu m, 0)$ \\
\hline $\mathrm{W}(\mathrm{m})$ & Waiting time & $\mathrm{w}(m)=\frac{L(m)}{f(0) \cdot \lambda}$ \\
\hline$f(0)$ & $\begin{array}{l}\text { Probability density of transport operators to leave at } 0 \\
\text { time }\end{array}$ & \\
\hline $\mathrm{t}$ & Every car's loading quantity & \\
\hline $\mathrm{r}$ & Transport price for each ton of cargo & \\
\hline$\lambda$ & Average arrival rate of freight cars & $P(X=k)=\frac{e^{-\lambda} \lambda^{k}}{k !}(k=0,1,2, \ldots)$ \\
\hline $\mathrm{p}$ & $\begin{array}{l}\text { The truck failed to reach the required time to pay the } \\
\text { loss of the supplier }\end{array}$ & \\
\hline $\mathrm{f}$ & $\begin{array}{l}\text { Other expenses paid by the transport operator(such as } \\
\text { tolls, oil fees, accommodation fees) }\end{array}$ & \\
\hline 400 & Information fees paid by the carrier to the integrator & \\
\hline
\end{tabular}




\section{Model Establishment and Analysis}

In this paper, we consider the benefits of the supplier and the carrier in the centralized product logistics. In this mode, the supplier and the carrier as the interest community, to achieve the maximization of the interests is to seek the greatest common interests. Therefore, we need to analyze the profit and the function of the supplier and the carrier, and obtain the optimal quantity $(\mathrm{m})$ and the price of each ton of goods $(\mathrm{R})$.

1, According to the above, now, the profits of the supplier and the carrier are expressed as follows (A: supplier; B: transport)

(1) Supplier's profit function:

$$
P^{A}=a \cdot m \cdot \mu+p-\lambda \cdot c_{w} \cdot w(m)-c_{a} \cdot L(m)
$$

The first in formula (1) said suppliers of goods on sale income; the second represents transport business payment to supplier in damages. The third represents the supplier payment to carrier waiting cost; the fourth said suppliers to pay for transport business to give up of cost.

$\mathrm{m} \cdot \mu$ :Total quantity of goods

$\lambda \cdot \mathrm{w}(m)$ :The total number of vehicles waiting to load

(2) Transport operator's profit function:

$$
P^{B}=r \cdot t-400-p-f
$$

The first in Formula (2) is to show that the goods cost; the second represents carriers pay to integrators of information costs; the third represents the transport business payment to suppliers of damages; the fourth said transport companies to pay other costs.

(3) Total profit of suppliers and transport

$$
P=P^{A}+P^{B}
$$

Bring A and B's profit function to the formula (3), and then get the

$$
P(\mathrm{r}, m)=a \cdot m \cdot \mu-\lambda \cdot c_{w} \cdot w(m)-c_{a} \cdot L(m)+r \cdot t-f-400
$$

Because: $\mathrm{w}(m)=\frac{L(m)}{f(0) \cdot \lambda}$

So:

$$
P(r, m)=a \cdot m \cdot \mu-\left[\frac{c_{w}}{f(0)}+c_{a}\right] \cdot L(m)+r \cdot t-f-400
$$

2, If the goods supplied by the supplier is equal to the carrying capacity of the carrier, the transport provider does not need to wait, and the supplier does not need to pay the cost of waiting and giving up. But in real life, due to various factors, the probability is small, so then we supply and loading of transport operators need to wait to carry on the analysis to the model.

Parameter description: $\mathrm{t} \cdot \lambda$ :Total load

$$
\mu \cdot \mathrm{m}: \text { Total supply }
$$

(1)when $\mathrm{t} \cdot \lambda \leq \mu \cdot m$, That is Total load $\leq$ Total supply, At this time there is no need to wait 
$P(r, m)=a \cdot m \cdot \mu-\left[\frac{c_{w}}{f(0)}+c_{a}\right] \cdot L(m)+r \cdot t-f-400$

Because: $L(m)=0$

So:

$$
P(r, m)=a \cdot m \cdot \mu+r \cdot t-f-400
$$

From the formula (6), we know that gross profit function $P(r, m)$ is about a increasing function of $\mathrm{m}$.

(2) when $\mathrm{t} \cdot \lambda \geq \mu \cdot m$, That is Total load $\geq$ Total supply, At this time need to wait $P(r, m)=a \cdot m \cdot \mu-\left[\frac{c_{w}}{f(0)}+c_{a}\right] \cdot L(m)+r \cdot t-f-400$

Because: $L(m)=\max (\lambda t-\mu m, 0)$

Also because $: \mathrm{t} \cdot \lambda \geq \mu \cdot m$

So: $L(m)=t \cdot \lambda-\mu \cdot m$

So:

$$
P(r, m)=\left[a \cdot \mu+\frac{\mu \cdot c_{w}}{f(0)}+\mu \cdot c_{a}\right] \cdot m-\left[\frac{c_{w}}{f(0)}+c_{a}\right] \cdot t \cdot \lambda+r \cdot t-f-400
$$

From the formula (7), we know that gross profit function $P(r, m)$ is about a increasing function of $\mathrm{m}$.

Because: $\mathrm{m} \leq \frac{t \cdot \lambda}{\mu}$

So : when $\mathrm{m}=\frac{\mathrm{t} \cdot \lambda}{\mu}$, Total profit maximization, That is : $P(r, m)=t \cdot r+a \cdot \lambda \cdot t-f-400$

(3) when $\mathrm{t} \cdot \lambda=\mu \cdot m$, That is Total load = Total supply

From (2),we know that The maximum total profit at this time is $P(r, m)=t \cdot r+a \cdot \lambda \cdot t-f-400$

\section{Example Analysis}

From the process of establishing and analyzing the model above, we know that the function of the total profit is

$$
P(r, m)=a \cdot m \cdot \mu-\left[\frac{c_{w}}{f(0)}+c_{a}\right] \cdot L(m)+r \cdot t-f-400
$$

Because the model is based on the maximum availability of $\mathrm{M}$ and the unit price of goods R

Function relationship, so that the maximum value of the total profit function, can be equivalent to the maximum value of the following functions.

$$
F(r, m)=a \cdot m \cdot \mu-\left[\frac{c_{w}}{f(0)}+c_{a}\right] \cdot L(m)+r \cdot t
$$

According to the actual situation to the variable assignment, specific as shown in Table 2 
Table 2 Variable assignment table

\begin{tabular}{|c|c|c|c|c|c|c|}
\hline $\mathrm{a}$ & $\mu$ & $c_{w}$ & $c_{a}$ & $\mathrm{f}(0)$ & $\mathrm{t}$ & $\lambda$ \\
\hline 1000 yuan/ton & 3days/times & $200 \mathrm{y} u a n /$ day & $2000 \mathrm{yuan}$ & $1 / 2$ & 20 ton & $1 / 4$ \\
\hline
\end{tabular}

Bring the specific numbers into the formula.

$F(r, m)=3000 m-2400 L(m)+20 \mathrm{r}$

(1)when $\mathrm{t} \cdot \lambda \leq \mu \cdot m$

$\max F(r, m)=3000 m+20 \mathrm{r}$

s.t $\left\{\begin{array}{c}m>\frac{5}{3} \\ r<1000 \\ m, r>0\end{array}\right.$

Function image as shown in Figure 2

\section{Total profit function}

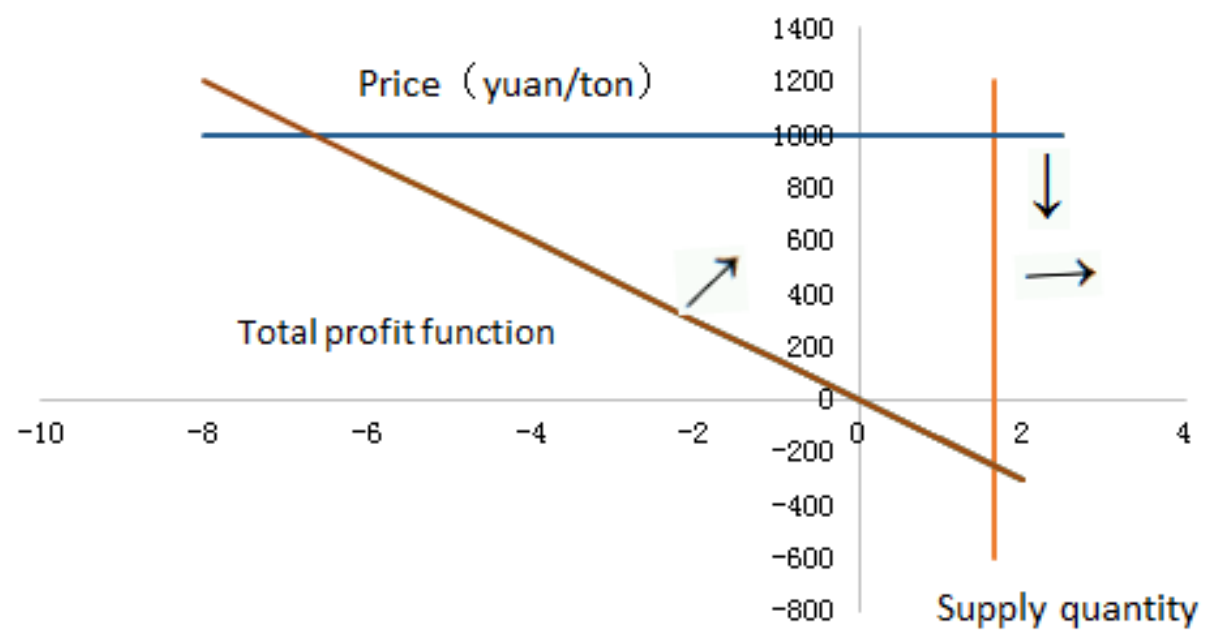

Figure 2 Total profit function

From the figure shows: the supplier pays the freight rate of not more than 1000 yuan / ton, supply not less than $5 / 3$, at this time, the feasible region can be extended to the right. The objective function has no maximum value, so this kind of situation has no optimal solution. Abandon.

(2) when $\mathrm{t} \cdot \lambda \geq \mu \cdot m$

there is: $L(m)=\lambda t-\mu m=5-3 m$

$\max F(r, m)=3000 m-2400 L(m)+20 \mathrm{r}=10200 \mathrm{~m}+20 \mathrm{r}-12000$

s.t $\left\{\begin{array}{c}m<\frac{5}{3} \\ r<1000 \\ m, r>0\end{array}\right.$

Function image as shown in Figure 3 


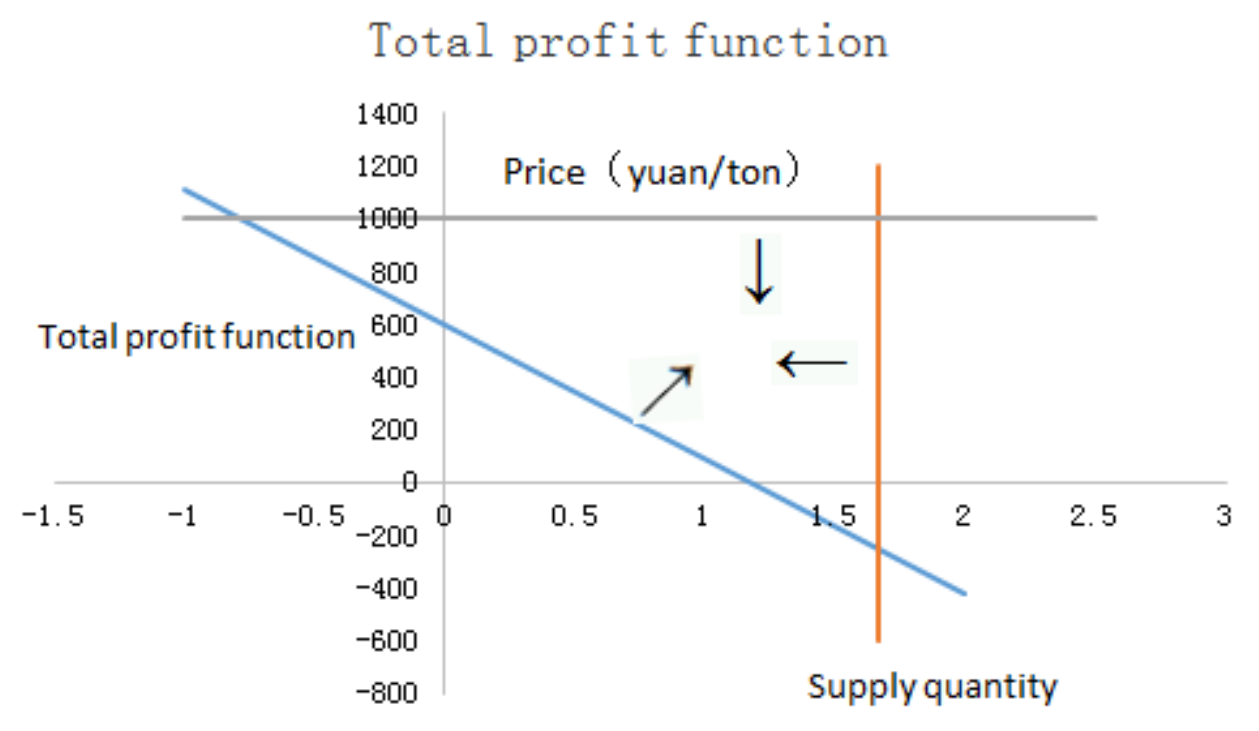

Figure 3 Total profit function

From the figure shows: the supplier shall pay to the carrier rate no more than 1000 yuan / ton, supply is not more than 5 / 3. At this point in the feasible region is a convex set. The objective function can obtain the maximum value, that is, the optimal solution.

(3) When the total amount of transportation and supply of goods is not equal, the total profit function as shown in Figure 4

\section{Total profit comparison function}

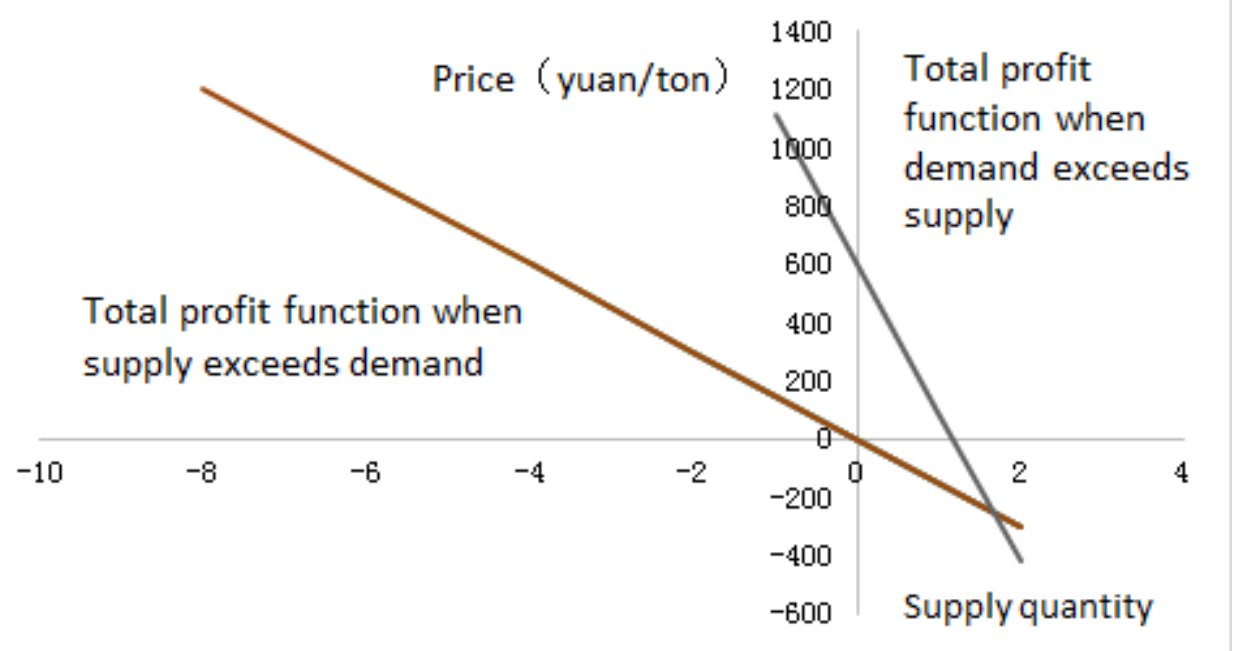

Figure 4 Comparison of total profit function

Comparing function figures we know: when supply quantity > loading capacity (Oversupply), The total profit affected by unit price of goods is very small , but affected by supply quantity is larger ; when supply quantity < loading capacity (Demand exceeds supply), The total profit affected by unit price of goods is larger than supply quantity . 


\section{Summary}

Through the analysis above, we can draw the following conclusions.

(1) In this paper, based on the actual situation, the paper establishes the model and analyzes the profit of the two parties in the centralized product logistics

(2) This paper solves the problems in the introduction: That is when the supplier and the carrier can realize the benefit maximization. The conclusion is that When the goods supplied by the supplier is equal to the number of carriers that the carrier can carry, the profits of the two parties are the largest. The conclusion is closely related to the actual life, which is of practical significance .

(3) With the rapid development of China's economy, the transportation industry is booming. However, for this kind of transportation management articles are not many, The contradiction between the supplier and the carrier is long existed. This paper focuses on resolving the conflict of interest between suppliers and carriers in order to realize mutual benefit and win-win situation.

However, due to the constraints of various conditions, I did not analyze the differences between fixed line carriers and non fixed line carriers in the whole logistics system. In real life, due to the imperfect social system, there is not a good way to solve the problem of Who should be responsible for the cost of waiting, giving up the cost. In this paper, according to the common sense, the waiting cost and the cost of giving up should be the responsibility of the supplier.

\section{Acknowledgement}

This research was financially supported by the National Natural Science Foundation of China [No.71401180].

\section{References}

[1]http://www.docin.com/p-354872598.html(In Chinese)

[2]http://www.cctv.com/special/362/4/32309.html(In Chinese)

[3]Jian-ming YAO. Supply chain scheduling optimization under the mode of mass customization. Operations research and management science.2015,(24)1:10-18(In Chinese)

[4]Gang XU, Jin QIN. Research on the influence of service relationship on the information sharing and trust decision of supply chain. Operations research and management science .2015,(24)5:11-17(In Chinese)

[5]Wen-long WANG, Xin-mei LIU, Tao WANG. Research on the coordination strategy of service supply chain based on customer queuing. Operations research and management science,2014.1(In Chinese)

[6]Xing HUANG ,Shao-yu WANG. Research on the strategy of emergency material reserve based on stability analysis. Operations research and management science,2014.1(In Chinese)

[7]Tao WU. Research on integrated supply chain operation and logistics management. Chinese HowNet.2003(In Chinese) 
[8]Shou-yang WANG ,Qiu-hong ZHAO,Guo-ping XIA. Research on location routing problem in integrated logistics management system. Journal of management science.2000,2(In Chinese)

[9]Yan XIAO ,Qi-lan ZHAO ,Hong-jie LAN. Logistics management under the environment of supply chain management. China's circulation economy.2001,5(In Chinese)

[10]Zhang HUA On Mathematics 9 mathematical modeling methods and analysis(In Chinese)

[11]José Crespo de Carvalho, João Vilas-Boas, Henrique O' Neill.Logistics and Supply Chain Management: An Area with a Strategic Service Perspective.American Journal of Industrial and Business Management, 2014, Vol.04 (01), pp.24-30

[12]Chang-Hsing Chang.A study of global logistics management strategies: based on the bicycle manufacturing.Journal of Statistics and Management Systems, 2009, Vol.12 (3), pp.543-559 